\title{
Differences in airway lumen area between supine and upright computed tomography in patients with chronic obstructive pulmonary disease
}

Shotaro Chubachi ${ }^{1}$, Yoshitake Yamada ${ }^{*}$ (1), Minoru Yamada ${ }^{2}$, Yoichi Yokoyama², Akiko Tanabe ${ }^{3}$, Shiho Matsuoka ${ }^{3}$, Yuki Niijima ${ }^{4}$, Wakako Yamasawa ${ }^{5}$, Hidehiro Irie ${ }^{1}$, Mitsuru Murata ${ }^{5}$, Koichi Fukunaga ${ }^{1}$ and Masahiro Jinzaki ${ }^{2 *}$

\begin{abstract}
Background: No clinical studies to date have compared the inspiratory and expiratory airway lumen area between supine and standing positions. Thus, the aims of this study were twofold: (1) to compare inspiratory and expiratory airway lumen area (IAA and EAA, respectively) on computed tomography (CT) among supine and standing positions; and (2) to investigate if IAA and EAA are associated with lung function abnormality in patients with chronic obstructive pulmonary disease (COPD).

Methods: Forty-eight patients with COPD underwent both low-dose conventional (supine position) and upright CT (standing position) during inspiration and expiration breath-holds and a pulmonary function test (PFT) on the same day. We measured the IAA and EAA in each position.

Results: For the trachea to the third-generation bronchi, the IAA was significantly larger in the standing position than in the supine position (4.1-4.9\% increase, all $p<0.05)$. The EAA of all bronchi was significantly larger in the standing position than in the supine position $(9.7-62.5 \%$ increases, all $p<0.001)$. The correlation coefficients of IAA in the standing position and forced expiratory volume in $1 \mathrm{~s}$ were slightly higher than those in the supine position. The correlation coefficients of EAA or EAA/IAA in the standing position and residual volume, and the inspiratory capacity/total lung capacity ratio were higher than those in the supine position.
\end{abstract}

Conclusions: Airway lumen areas were larger in the standing position than in the supine position. IAAs reflect airway obstruction, and EAAs reflect lung hyperinflation. Upright CT might reveal these abnormalities more precisely. Trial registration University Hospital Medical Information Network (UMIN 000026587), Registered 17 March 2017. URL: https://upload.umin.ac.jp/cgi-open-bin/ctr/ctr_view.cgi?recptno=R000030456.

Keywords: COPD, CT, Pulmonary function test

*Correspondence: yamada@rad.med.keio.ac.jp; jinzaki@rad.med.keio.ac.jp 2 Department of Radiology, Keio University School of Medicine, 35 Shinanomachi, Shinjuku-ku, Tokyo 160-8582, Japan

Full list of author information is available at the end of the article

\section{Background}

Chronic obstructive pulmonary disease (COPD) is a common, preventable, and treatable disease characterised by persistent respiratory symptoms and airflow limitation [1]. Airflow limitation in COPD is caused by decreased elastic recoil due to emphysematous original author(s) and the source, provide a link to the Creative Commons licence, and indicate if changes were made. The images or other third party material in this article are included in the article's Creative Commons licence, unless indicated otherwise in a credit line to the material. If material is not included in the article's Creative Commons licence and your intended use is not permitted by statutory regulation or exceeds the permitted use, you will need to obtain permission directly from the copyright holder. To view a copy of this licence, visit http://creativecommons.org/licenses/by/4.0/. The Creative Commons Public Domain Dedication waiver (http://creativeco mmons.org/publicdomain/zero/1.0/) applies to the data made available in this article, unless otherwise stated in a credit line to the data. 
destruction and small airways disease [2, 3]. Chest computed tomography (CT) can quantify these two main causes of COPD. Although small airways cannot be directly visualised by chest $\mathrm{CT}$, a previous report has shown that CT measurements of central airway dimensions can estimate the dimensions of the histological small airways [4]. Early measurements of the airways have relied on manual tracing, but several automated methods have been developed. Previous reports using automated methods have shown that the mean lumen area of the 3rd to 6th generation airways reflects airflow limitation in patients with COPD $[5,6]$.

Objective measures of airway disease and emphysema have been well established using inspiratory CT [7]. Recently, central airway collapse using expiratory CT has been reported as an important clinical parameter in patients with COPD. Tracheal collapse during exhalation is prevalent in patients with COPD and related to worse St. George's Respiratory Questionnaire (SGRQ) scores and frequent exacerbation in these patients [8, 9]. However, only a few reports have shown that expiratory bronchial area and expiratory bronchial collapse can be CT biomarkers that reflect lung function abnormalities in patients with COPD $[10,11]$.

Lung hyperinflation is a crucial pathophysiological mechanism in the development of dyspnoea and exercise intolerance in patients with COPD [12]. Furthermore, it is a predictor of mortality in these patients [13]. Although lung hyperinflation is an important clinical indicator in patients with COPD, the relationship between the degree of lung hyperinflation and mean airway lumen area in inspiratory and expiratory CT has not been elucidated.

Recently, a 320-detector-row upright CT scanner has been developed to evaluate human anatomy in the upright position three-dimensionally, and clarify the effects of gravity on the human body [14]. In a previous report of healthy volunteers, we showed that the inspiratory and expiratory bilateral lung volumes were significantly higher in the standing position than in the supine position using an upright CT scanner $[15,16]$. To the best of our knowledge, no clinical studies to date have accurately compared both the inspiratory and expiratory airway lumen areas (IAA and EAA, respectively) in the supine and standing positions. We hypothesised that the IAA, EAA and EAA/IAA ratio between supine and standing positions would be different, because the direction of gravity relative to the chest differs between the supine and upright positions. Thus, the aims of this study were: (1) to compare the airway lumen area on inspiratory and expiratory CT between supine and standing positions; and (2) to compare the relationship between airway lumen area on inspiratory and expiratory $\mathrm{CT}$ and lung function abnormalities such as airflow limitation and lung hyperinflation in patients with COPD.

\section{Methods \\ Study population}

This prospective study was approved by the Keio University School of Medicine Ethics Committee (No. 20160385). Written informed consent was obtained from all patients (UMIN Clinical Trials Registry [UMINCTR]: UMIN000026587). From August 2018 to September 2019, a total of 51 consecutive patients with known COPD, who were scheduled for clinical CT examination, were considered for inclusion in this prospective study. The exclusion criteria were as follows: age $<20$ years old $(\mathrm{n}=0)$; pregnant or unknown pregnancy status in patients of childbearing potential $(n=0)$; not able to undergo $\mathrm{CT}$ in a standing position $(\mathrm{n}=0)$; not willing to provide written informed consent $(\mathrm{n}=0)$; and forced expiratory volume in $1 \mathrm{~s}\left(\mathrm{FEV}_{1}\right) /$ forced vital capacity $(\mathrm{FVC})>70 \%$ on the day of the upright and conventional CT examinations $(n=3)$. Thus, 48 patients were included in this study.

\section{CT imaging protocol}

All patients underwent conventional chest low-dose $\mathrm{CT}$ in the supine position with arms raised using a 320-detector-row CT (Aquilion ONE, Canon Medical Systems, Otawara, Japan), and upright chest lowdose CT in the standing position with arms down using a 320-detector-row upright CT (prototype TSX-401R, Canon Medical Systems) on the same day [14-17]. The chest scans in the two positions were unenhanced and were performed during both deep-inspiration and expiration breath-holds, with automatic exposure control using a noise index of 24 for a slice thickness of $5 \mathrm{~mm}$ (tube current range, 10-350 mA). The following scanning parameters were also the same for the supine and standing chest CT scans: peak tube voltage, $120 \mathrm{kVp}$; rotation speed, $0.5 \mathrm{~s}$; slice collimation, $0.5 \mathrm{~mm} \times 80$; and pitch factor, 0.813 . The series of contiguous $0.5-\mathrm{mm}$ thick images were reconstructed with Adaptive Iterative Dose Reduction 3D (Canon Medical Systems) [18]. The CT dose index volumes for the inspiratory supine CT, expiratory supine $\mathrm{CT}$, inspiratory upright $\mathrm{CT}$, and expiratory upright $\mathrm{CT}$ were $2.76 \pm 0.53,2.74 \pm 0.54,3.05 \pm 0.61$, and $3.36 \pm 0.68 \mathrm{mGy}$, respectively; the dose-length products were $120.0 \pm 27.0,99.9 \pm 19.0,138.8 \pm 28.2$, and $127.0 \pm 26.0 \mathrm{mGy}-\mathrm{cm}$, respectively; the effective dose estimates were $1.68 \pm 0.38,1.40 \pm 0.27,1.94 \pm 0.39$, and $1.78 \pm 0.36 \mathrm{mSv}$, respectively, and were determined by the dose-length product measurements and the appropriate normalised coefficient found in the literature for chest CT $(0.014 \mathrm{mSv} /(\mathrm{mGy}-\mathrm{cm})$ [19]. Thus, the total effective 
dose estimate for the four CT examinations in this study was approximately $6.8 \mathrm{mSv}$, which is slightly less than that for a single routine clinical chest CT (7 mSv) [20]. Examples of low-dose conventional (supine position) and upright CT (standing position) images are shown in Fig. 1.

\section{Segmentation and measurement of the airway lumen}

Airway segmentation and airway luminal area measurements were obtained using SYNAPSE VINCENT software (FUJIFILM Medical, Tokyo, Japan) ${ }^{5}$. The segmental bronchus was defined as the 3rd generation airway. Following automatic luminal segmentation of the airway tree, all branches of the 3rd to 6th generation airways in all segments were manually identified by tracking from the 3rd to the 6th generation $[5,21]$. For each branch, cross-sectional images perpendicular to the longitudinal center line of the lumen were generated, and the lumen areas and internal diameters in the middle third portion were automatically measured and averaged. The mean

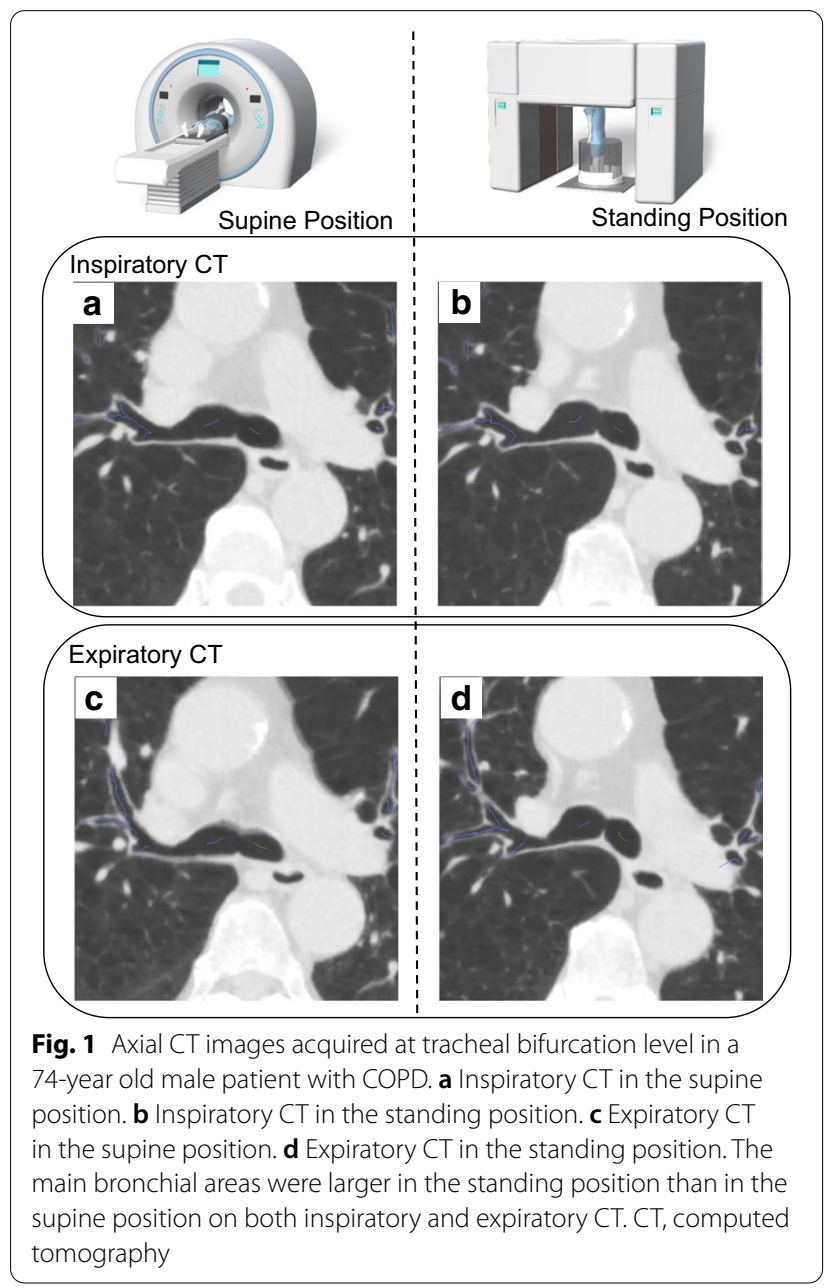

lumen area for each generation airway was calculated in all segments.

\section{Pulmonary function test}

All participants underwent a pulmonary function test (PFT) on the same day as they underwent both conventional and upright CT examinations (within two $h$ of the CT examinations). The PFT was performed in a stable condition, with the patient in a sitting position, using a spirometer (Chestac-8900, Chest M.I., Tokyo, Japan) in accordance with ATS/European Respiratory Society recommendations $[22,23]$. The residual volume and TLC were measured by the multi-breath helium dilution method. Predicted values of spirometric measurements were derived from the guidelines of the Japanese Respiratory Society $[24,25]$.

\section{Statistical analysis}

Data are presented as means \pm standard deviation (SD) or medians (interquartile range ([IQR]). Wilcoxon signed-rank test was performed to analyse differences in the airway lumen area between the supine and standing positions. The association between the airway lumen area in each position and parameters on PFT was evaluated by Spearman's correlation test. The significance level for all tests was 5\% (two-sided). All data were analysed using a commercially available software program (JMP version 14; SAS Institute Inc, Cary, NC, USA).

\section{Results}

Characteristics of the study population

The clinical characteristics of the study population are shown in Table 1 . The median age of the patients with COPD was 77 years (IQR, 71-81); 91.7\% were men, and $4.2 \%$ were current smokers. The number of patients with

Table 1 Baseline characteristics of the study population

\begin{tabular}{|c|c|}
\hline & $N=48$ \\
\hline Sex, female, (\%) & $4(8.3)$ \\
\hline Age, years & $77(71-81)$ \\
\hline Smoking index, pack-years & $50.0(30.0-76.9)$ \\
\hline Current smokers, (\%) & $2.0(4.2)$ \\
\hline $\mathrm{BMI}, \mathrm{kg} / \mathrm{m}^{2}$ & $23.4 \pm 3.2$ \\
\hline $\mathrm{FEV}_{1} / \mathrm{FVC},(\%)$ & $51.7(43.9-61.4)$ \\
\hline$\% \mathrm{FEV}_{1},(\%)$ & $69.8 \pm 19.1$ \\
\hline COPD grades* $1 / 2 / 3 / 4,(\%)$ & $\begin{array}{l}14 / 27 / 6 / 1 \\
(29.2 / 56.3 / 12.5 / 2.0)\end{array}$ \\
\hline
\end{tabular}

Data are presented as mean $\pm S D$, medians (IQR), or number (\%). * Defined by the Global Initiative for Chronic Obstructive Lung Disease. BMI, body mass index; $\mathrm{FEV}_{1}$, forced expiratory volume in $1 \mathrm{~s}$; FVC, forced vital capacity; \%FEV ${ }_{1}$, forced expiratory volume in $1 \mathrm{~s}$ as a percentage of predicted forced expiratory volume in $1 \mathrm{~s}$; COPD, chronic obstructive pulmonary disease; GOLD, Global Initiative for Chronic Obstructive Lung Disease 
COPD among the Global Initiative for Chronic Obstructive Lung Disease (GOLD) grades 1, 2, 3, and 4 were 14, 27,6 , and 1 , respectively.

\section{Comparison of the airway lumen area on inspiratory and expiratory $\mathrm{CT}$ between supine and standing positions}

The evaluations of the airway lumen areas on inspiratory and expiratory CT scans are shown in Table 2. For the trachea to the 3rd generation bronchi, IAA was significantly larger in the standing position than in the supine position (trachea: 354.1 , IQR $316.1-396.7$ vs. 368.6, IQR 328.5-400.3, $\mathrm{p}=0.0003$; main bronchus: 195.4, IQR 176.2-229.2, vs. 204.9, IQR 188.4-231.7, $\mathrm{p}=0.0098$; 3rd generation bronchi: 115.3, IQR 97.9-141.0, vs. 120.5, IQR 98.9-147.4, $\mathrm{p}=0.0359$; supine vs. standing position, respectively).

In contrast to the results of inspiratory $\mathrm{CT}$, expiratory CT showed that the EAA of all bronchi was significantly larger in the standing position than in the supine position (trachea: 300.7, IQR 269.4-332.9, vs. 329.8, IQR 294.4-355.7, $\mathrm{p}<0.0001$; main bronchus: 147.5, IQR 91.6-175.1, vs. 184.3, IQR 160.8-206.9, p<0.0001; 3rd generation bronchi: 69.8 , IQR $48.5-92.0$, vs. 82.6 , IQR 67.3-109.0, $\mathrm{p}<0.0001$; 4th generation bronchi: 23.5 , IQR,

Table 2 Comparison of airway lumen area at inspiratory and expiratory CT between the supine and standing positions

\begin{tabular}{|c|c|c|c|}
\hline Generation & Supine & Standing & $p$ value \\
\hline \multicolumn{4}{|l|}{ IAA } \\
\hline Trachea & $354.1(316.1-396.7)$ & $368.6(328.5-400.3)$ & 0.0003 \\
\hline Main bronchus & $195.4(176.2-229.2)$ & $204.9(188.4-231.7)$ & 0.0098 \\
\hline $3 r d$ & $115.3(97.9-141.0)$ & $120.5(98.9-147.4)$ & 0.0359 \\
\hline 4 th & $48.2(38.1-58.6)$ & $47.1(36.4-61.4)$ & 1.0000 \\
\hline 5 th & $24.4(18.2-27.8)$ & $23.6(17.1-31.2)$ & 0.996 \\
\hline 6th & $11.7(9.5-17.8)$ & $11.6(9.1-16.4)$ & 0.1852 \\
\hline \multicolumn{4}{|l|}{ EAA } \\
\hline Trachea & 300.7 (269.4-332.9) & $329.8(294.4-355.7)$ & $<0.0001$ \\
\hline Main bronchus & $147.5(91.6-175.1)$ & $184.3(160.8-206.9)$ & $<0.0001$ \\
\hline $3 \mathrm{rd}$ & $69.8(48.5-92.0)$ & $82.6(67.3-109.0)$ & $<0.0001$ \\
\hline 4 th & $23.5(14.5-35.0)$ & $30.0(21.0-36.3)$ & 0.0063 \\
\hline 5th & $9.7(4.8-14.6)$ & $12.6(8.5-18.6)$ & 0.0006 \\
\hline 6th & $3.2(1.5-6.4)$ & $5.2(2.7-8.3)$ & 0.0018 \\
\hline \multicolumn{4}{|l|}{ EAA/IAA } \\
\hline Trachea & $0.84(0.76-0.90)$ & $0.90(0.84-0.95)$ & $<0.0001$ \\
\hline Main bronchus & $0.74(0.50-0.85)$ & $0.87(0.80-1.00)$ & $<0.0001$ \\
\hline $3 r d$ & $0.65(0.42-0.77)$ & $0.78(0.59-0.90)$ & $<0.0001$ \\
\hline 4 th & $0.52(0.35-0.68)$ & $0.62(0.45-0.78)$ & 0.0059 \\
\hline 5 th & $0.40(0.22-0.53)$ & $0.53(0.33-0.78)$ & 0.0002 \\
\hline 6th & $0.29(0.15-0.45)$ & $0.45(0.22-0.66)$ & 0.0002 \\
\hline
\end{tabular}

Data are presented as medians (IQR). IAA, inspiratory airway lumen area; EAA, expiratory airway lumen area; EAA/IAA; expiratory airway lumen area/inspiratory airway lumen area ratio
14.5-35.0, vs. 30.0, IQR 21.0-36.3, $\mathrm{p}=0.0063$; 5 th generation bronchi: 9.7, IQR 4.8-14.6, vs. 12.6, IQR 8.5-18.6, $\mathrm{p}=0.0006$; 6th generation bronchi: 3.2 , IQR 1.5-6.4, vs. 5.2, IQR 2.7-8.3, $\mathrm{p}=0.0018$; supine vs. standing position, respectively).

On paired inspiratory and expiratory CT scans, the EAA/IAA of all bronchi was significantly larger in the standing position than in the supine position (trachea: 0.84, IQR 0.76-0.90, vs. 0.90, IQR 0.84-0.95, p < 0.0001; main bronchus: 0.74 , IQR $0.50-0.85$, vs. 0.87 , IQR $0.80-1.00, \mathrm{p}<0.0001$; 3rd generation bronchi: 0.65, IQR, 0.42-0.77, vs. 0.78, IQR 0.59-0.90, $\mathrm{p}<0.0001$; 4th generation bronchi: 0.52 , IQR $0.35-0.68$, vs. 0.62 , IQR $0.45-0.78, \mathrm{p}=0.0059$; 5 th generation bronchi: 0.40 , IQR $0.22-0.53$, vs. 0.53 , IQR $0.33-0.78, \mathrm{p}=0.0002$; 6th generation bronchi: 0.29 , IQR $0.15-0.45$, vs. 0.45 , IQR $0.22-0.66, \mathrm{p}=0.0002$; supine vs. standing position, respectively). These results showed that bronchial lumen area expanded from the supine to the standing position, especially in expiratory CT.

\section{Correlations of airway lumen area at inspiratory CT in the supine and standing positions with the results of the PFT}

The correlations between the IAA and the results of the PFT are shown in Table 3. For the 3rd to the 5th generation bronchi, IAA was significantly correlated with $\mathrm{FEV}_{1}$ and $\% \mathrm{FEV}_{1}$ in the supine position (3rd generation bronchi: $\mathrm{FEV}_{1}, \rho=0.43$; $\% \mathrm{FEV}_{1}, \rho=0.44$; 4th generation bronchi: $\mathrm{FEV}_{1}, \rho=0.38 ; \% \mathrm{FEV}_{1}, \rho=0.41$; 5 th generation bronchi: $\mathrm{FEV}_{1}, \rho=0.38$; $\% \mathrm{FEV}_{1}, \rho=0.34$; all $\left.\mathrm{p}<0.05\right)$. For the main bronchus to the 6th generation bronchi, IAA was significantly correlated with $\mathrm{FEV}_{1}$ and $\% \mathrm{FEV}_{1}$ in the standing position (main bronchus: $\mathrm{FEV}_{1}, \rho=0.32$; $\% \mathrm{FEV}_{1}$, $\rho=0.39$; 3rd generation bronchi: $\mathrm{FEV}_{1}, \rho=0.50$; $\% \mathrm{FEV}_{1}$, $\rho=0.45$; 4th generation bronchi: $\mathrm{FEV}_{1}, \rho=0.50$; $\% \mathrm{FEV}_{1}$, $\rho=0.41$; 5th generation bronchi: $\mathrm{FEV}_{1}, \rho=0.43$; $\% \mathrm{FEV}_{1}$, $\rho=0.38$; 6th generation bronchi: $\mathrm{FEV}_{1}, \rho=0.40$; $\% \mathrm{FEV}_{1}$, $\rho=0.29$; all $\mathrm{p}<0.05)$. RV, \%RV and IC/TLC did not correlate with IAA both in the supine and standing positions, except for the 3rd generation bronchi with \%RV (supine: $\rho=-0.39$; standing: $\rho=-0.33$ ). These results showed that the airway lumen area on inspiratory CT predicted airway obstruction but could not predict lung hyperinflation, and the correlation between IAA and the degree of airway obstruction was greater in the standing position than the supine position. 
Table 3 Correlations of airway lumen area at inspiratory CT in the supine and standing positions with the results of the pulmonary function test

\begin{tabular}{|c|c|c|c|c|c|}
\hline Generation & Supine & Standing & Generation & Supine & Standing \\
\hline $\mathrm{FEV}_{1}$ & & & $\mathrm{RV}$ & & \\
\hline Trachea & 0.22 & 0.24 & Trachea & 0.10 & 0.06 \\
\hline $\begin{array}{l}\text { Main bron- } \\
\text { chus }\end{array}$ & 0.25 & $0.32^{* *}$ & $\begin{array}{l}\text { Main bron- } \\
\text { chus }\end{array}$ & -0.04 & -0.08 \\
\hline $3 r d$ & $0.43^{* *}$ & $0.50^{* *}$ & $3 r d$ & -0.18 & -0.08 \\
\hline 4 th & $0.38^{* *}$ & $0.50^{* *}$ & 4 th & -0.11 & -0.07 \\
\hline 5 th & $0.38^{* *}$ & $0.43^{* *}$ & 5 th & -0.12 & -0.06 \\
\hline 6 th & $0.32^{*}$ & $0.40^{* *}$ & 6th & -0.05 & -0.09 \\
\hline$\% \mathrm{FEV}_{1}$ & & & $\% \mathrm{RV}$ & & \\
\hline Trachea & 0.05 & 0.23 & Trachea & -0.13 & -0.16 \\
\hline $\begin{array}{l}\text { Main bron- } \\
\text { chus }\end{array}$ & 0.21 & $0.39^{* *}$ & $\begin{array}{l}\text { Main bron- } \\
\text { chus }\end{array}$ & -0.25 & -0.21 \\
\hline $3 r d$ & $0.44^{* *}$ & $0.45^{* *}$ & $3 r d$ & $-0.39^{*}$ & $-0.33^{*}$ \\
\hline 4th & $0.41^{* *}$ & $0.41^{* *}$ & 4 th & -0.26 & -0.22 \\
\hline 5 th & $0.34^{*}$ & $0.38^{* *}$ & 5 th & -0.21 & -0.16 \\
\hline \multirow[t]{8}{*}{ 6th } & 0.21 & $0.29^{*}$ & 6th & -0.12 & -0.13 \\
\hline & & & IC/TLC & & \\
\hline & & & Trachea & 0.07 & 0.11 \\
\hline & & & $\begin{array}{l}\text { Main bron- } \\
\text { chus }\end{array}$ & 0.17 & 0.07 \\
\hline & & & $3 r d$ & 0.26 & 0.20 \\
\hline & & & 4th & 0.12 & 0.08 \\
\hline & & & 5 th & -0.01 & -0.06 \\
\hline & & & 6th & -0.05 & -0.03 \\
\hline
\end{tabular}

*and ** indicate $\mathrm{p}<0.05$ and $\mathrm{p}<0.01$, respectively. $\mathrm{FEV}_{1}$, forced expiratory volume in $1 \mathrm{~s} ; \% \mathrm{FEV}_{1}$, forced expiratory volume in $1 \mathrm{~s}$ as a percentage of predicted forced expiratory volume in $1 \mathrm{~s}$; RV, residual volume; \%RV, residual volume as a percentage of predicted residual volume; IC/TLC; inspiratory capacity/total lung capacity ratio
Table 4 Correlations of airway lumen area on expiratory CT in the supine and standing positions with the results of the pulmonary function test

\begin{tabular}{|c|c|c|c|c|c|}
\hline Generation & Supine & Standing & Generation & Supine & Standing \\
\hline $\mathrm{FEV}_{1}$ & & & $\mathrm{RV}$ & & \\
\hline Trachea & 0.24 & 0.26 & Trachea & 0.19 & 0.24 \\
\hline $\begin{array}{l}\text { Main bron- } \\
\text { chus }\end{array}$ & $0.29^{*}$ & 0.05 & $\begin{array}{l}\text { Main bron- } \\
\text { chus }\end{array}$ & $0.31^{*}$ & 0.20 \\
\hline $3 r d$ & $0.35^{*}$ & $0.31^{*}$ & $3 r d$ & $0.37^{* *}$ & $0.37^{* *}$ \\
\hline 4 th & $0.29 *$ & $0.34^{*}$ & 4th & $0.29 *$ & $0.32^{*}$ \\
\hline 5 th & 0.28 & 0.19 & 5 th & $0.28^{*}$ & $0.30^{*}$ \\
\hline 6th & 0.24 & 0.15 & 6th & $0.33^{*}$ & $0.39^{*}$ \\
\hline$\% \mathrm{FEV}_{1}$ & & & $\% R V$ & & \\
\hline Trachea & 0.05 & 0.12 & Trachea & -0.01 & -0.06 \\
\hline $\begin{array}{l}\text { Main bron- } \\
\text { chus }\end{array}$ & 0.02 & -0.04 & $\begin{array}{l}\text { Main bron- } \\
\text { chus }\end{array}$ & 0.04 & 0.10 \\
\hline $3 r d$ & 0.11 & 0.07 & $3 r d$ & 0.07 & 0.12 \\
\hline 4th & 0.07 & 0.17 & 4th & 0.08 & 0.12 \\
\hline 5 th & 0.10 & 0.12 & 5 th & 0.11 & 0.21 \\
\hline \multirow[t]{8}{*}{ 6th } & 0.10 & 0.03 & 6th & 0.19 & $0.31^{*}$ \\
\hline & & & IC/TLC & & \\
\hline & & & Trachea & 0.02 & 0.02 \\
\hline & & & $\begin{array}{l}\text { Main bron- } \\
\text { chus }\end{array}$ & -0.02 & -0.08 \\
\hline & & & $3 r d$ & -0.09 & -0.16 \\
\hline & & & 4th & -0.15 & -0.23 \\
\hline & & & 5 th & -0.14 & $-0.37^{*}$ \\
\hline & & & 6th & -0.22 & $-0.43^{*}$ \\
\hline
\end{tabular}

* and ** indicate $\mathrm{p}<0.05$ and $\mathrm{p}<0.01$, respectively. $\mathrm{FEV}_{1}$, forced expiratory volume in $1 \mathrm{~s} ; \% \mathrm{FEV}_{1}$, forced expiratory volume in $1 \mathrm{~s}$ as a percentage of predicted forced expiratory volume in $1 \mathrm{~s}$; RV, residual volume; \%RV, residual volume as a percentage of predicted residual volume; IC/TLC; inspiratory capacity/total lung capacity ratio

results showed that the airway lumen area on expiratory CT predicts lung hyperinflation more precisely than airway obstruction, and the correlation between EAA and the degree of lung hyperinflation was slightly greater in the standing position than the supine position.

\section{Correlations of EAA/IAA in the supine and standing positions with the results of the PFT}

The correlations of EAA/IAA on paired inspiratory and expiratory $\mathrm{CT}$ scans with the results of the pulmonary function test are shown in Table 5. EAA/IAA in the supine and standing positions was significantly correlated with RV (main bronchus: $\rho=0.40$ vs. $\rho=0.44$; 3rd generation bronchi: $\rho=0.50$ vs. $\rho=0.42$; 4 th generation bronchi: $\rho=0.36$ vs. $\rho=0.30$; 5 th generation bronchi: $\rho=0.35$ vs. $\rho=0.33$; 6 th generation bronchi: $\rho=0.37$ vs. $\rho=0.44$; supine vs. standing position, respectively; all $\mathrm{p}<0.05)$ and \% RV (main bronchus in the standing position: $\rho=0.34$; related with IC/TLC (5th generation bronchi: $p=-0.37$; 6th generation bronchi: $\rho=-0.43$; all $\mathrm{p}<0.05)$. These 
Table 5 Correlations of EAA/IAA in supine and standing positions with the results of the pulmonary function test

\begin{tabular}{|c|c|c|c|c|c|}
\hline Generation & Supine & Standing & Generation & Supine & Standing \\
\hline $\mathrm{FEV}_{1}$ & & & RV & & \\
\hline Trachea & 0.19 & 0.03 & Trachea & 0.11 & 0.28 \\
\hline $\begin{array}{l}\text { Main bron- } \\
\text { chus }\end{array}$ & 0.18 & -0.20 & $\begin{array}{l}\text { Main bron- } \\
\text { chus }\end{array}$ & $0.40^{* *}$ & $0.44^{* *}$ \\
\hline $3 r d$ & 0.15 & -0.13 & $3 r d$ & $0.50^{* *}$ & $0.42^{* *}$ \\
\hline 4 th & 0.04 & -0.03 & 4th & $0.36^{*}$ & $0.30^{*}$ \\
\hline 5th & 0.09 & -0.07 & 5 th & $0.35^{*}$ & $0.33^{*}$ \\
\hline 6th & 0.12 & -0.01 & 6th & $0.37^{* *}$ & $0.44^{* *}$ \\
\hline$\% F_{1}$ & & & $\% \mathrm{RV}$ & & \\
\hline Trachea & 0.11 & -0.10 & Trachea & -0.01 & 0.19 \\
\hline $\begin{array}{l}\text { Main bron- } \\
\text { chus }\end{array}$ & -0.08 & $-0.39^{*}$ & $\begin{array}{l}\text { Main bron- } \\
\text { chus }\end{array}$ & 0.15 & $0.34^{*}$ \\
\hline $3 r d$ & -0.10 & -0.28 & $3 r d$ & $0.33^{*}$ & $0.40^{* *}$ \\
\hline 4th & 0.15 & -0.15 & 4th & $0.29^{*}$ & $0.29^{*}$ \\
\hline 5th & -0.06 & -0.12 & 5 th & 0.25 & $0.35^{*}$ \\
\hline \multirow[t]{8}{*}{ 6th } & -0.02 & -0.12 & 6 th & $0.29^{*}$ & $0.39^{* *}$ \\
\hline & & & IC/TLC & & \\
\hline & & & Trachea & -0.04 & -0.18 \\
\hline & & & $\begin{array}{l}\text { Main bron- } \\
\text { chus }\end{array}$ & -0.004 & -0.19 \\
\hline & & & $3 r d$ & -0.26 & $-0.37^{* *}$ \\
\hline & & & 4th & -0.23 & $-0.33^{* *}$ \\
\hline & & & 5th & -0.16 & $-0.37^{* *}$ \\
\hline & & & 6th & -0.23 & $-0.38^{* *}$ \\
\hline
\end{tabular}

* and ** indicate $\mathrm{p}<0.05$ and $\mathrm{p}<0.01$, respectively. $\mathrm{FEV}_{1}$, forced expiratory volume in $1 \mathrm{~s} ; \% \mathrm{FEV}_{1}$, forced expiratory volume in $1 \mathrm{~s}$ as a percentage of predicted forced expiratory volume in $1 \mathrm{~s}$; RV, residual volume; \%RV, residual volume as a percentage of predicted residual volume; IC/TLC; inspiratory capacity/total lung capacity ratio

3rd generation bronchi: $\rho=0.33$ vs. $\rho=0.40$; 4 th generation bronchi: $\rho=0.29$ vs. $\rho=0.29$; 5 th generation bronchi in the standing position: $\rho=0.35$; 6 th generation bronchi: $\rho=0.29$ vs. $\rho=0.39$; supine vs. standing position, respectively; all $\mathrm{p}<0.05)$. EAA/IAA in the supine position was not correlated with IC/TLC, but that in the standing position was significantly correlated with $\mathrm{IC} /$ TLC for the 3rd generation to the 6th generation bronchi (3rd generation bronchi: $\rho=-0.37$; 4 th generation bronchi: $\rho=-0.33$; 5 th generation bronchi: $\rho=-0.37$; 6th generation bronchi: $\rho=-0.38$; all $\mathrm{p}<0.05)$. $\mathrm{FEV}_{1}$ and $\% \mathrm{FEV}_{1}$ were not correlated with EAA/IAA both in the supine and standing positions, except for the main bronchus in the standing position, which was correlated with $\% \mathrm{FEV}_{1}(\rho=-0.39, \mathrm{p}<0.05)$. These results show that the ratio of the airway lumen area on inspiratory and expiratory CT scans predicts lung hyperinflation but does not predict airway obstruction, and the correlation between the EAA/IAA and lung hyperinflation was greater in the standing position than the supine position.

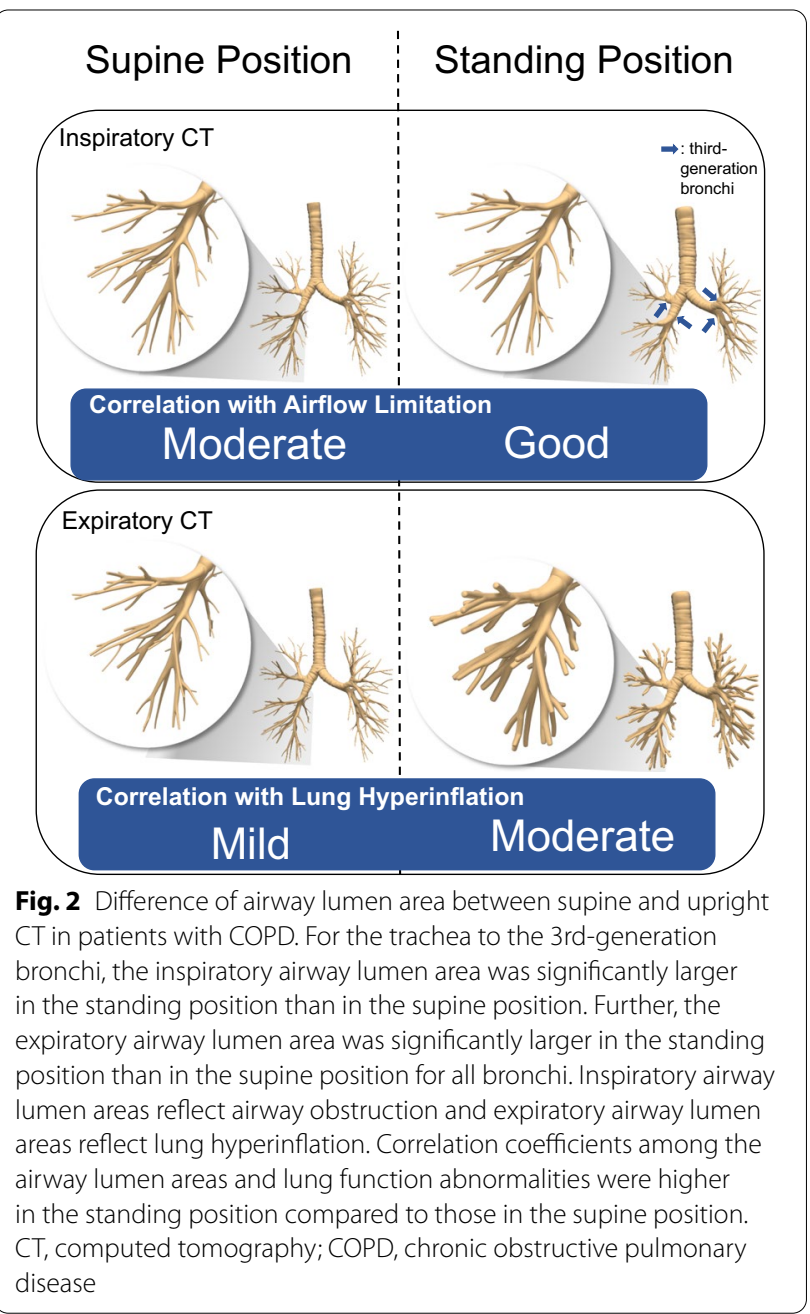

\section{Discussion}

To the best of our knowledge, this is the first study to show the difference in the airway lumen area between spine and standing position CT scans. The schema of this study is shown in Fig. 2. Our study provided three novel observations of potential relevance. First, the bronchial lumen area was larger in the standing position compared to that in the supine position on both inspiratory and expiratory CT. Second, IAA predicted airflow limitation, and both EAA and EAA/IAA predicted lung hyperinflation. Third, upright CT could predict airflow limitation and lung hyperinflation more precisely than conventional supine CT.

Our study showed that the bronchial lumen area, especially in the proximal airway, was larger in the standing position compared to that in the supine position. A possible reason for this was the difference of gravity on the bronchial lumen between the supine and standing positions. Changing gravity affects the upper airway area, lung volume and chest wall movement [26, 27]. It 
is possible that gravity directly changes the area of the trachea and bronchi, or indirectly changes the area of the airway, by changing abdominal and intrathoracic pressure via changing the movement of the tracheal smooth muscle, intercostal muscle and diaphragm. Recently, dynamic expiratory tracheal collapse has been reported as being a clinical indicator for predicting health status and future exacerbation in patients with COPD [9]. However, another report has shown that the magnitude of tracheal collapse is independent of disease severity and does not correlate significantly with physiologic parameters in patients with COPD [28]. This discrepancy might be caused by the difficulty in accurately measuring the magnitude of the collapse. The amount of collapse might be captured at arbitrary points in the respiratory cycle, potentially missing the inspiratory maximum and/ or expiratory minimum [29]. Precise measurement of the dynamic expiratory tracheal collapse using upright CT might predict the clinical characteristics of patients with COPD. Thus, the clinical characteristics of having dynamic expiratory tracheal collapse in the standing position warrants further investigation.

In this study, the IAA for the 3rd to 5th generation bronchi was correlated with $\% \mathrm{FEV}_{1}$ in the supine position, which was consistent with the results of previous reports using conventional supine $\mathrm{CT}[5,6]$. Further, the IAA for the main bronchus to the 6th generation bronchi was correlated with $\% \mathrm{FEV}_{1}$ in the standing position. The correlation between the IAA and $\% \mathrm{FEV}_{1}$ was stronger, and the IAA predicted $\% \mathrm{FEV}_{1}$ in a wider range in the standing position compared to that in the supine position. A previous study reported that a change in the airway lumen area before and after bronchodilator treatment was a useful biomarker in patients with COPD [30]. Thus, accurate evaluation of changes to the airway lumen area using upright $\mathrm{CT}$ could be used to determine therapeutic effects in patients with COPD.

In the inspiratory $\mathrm{CT}$, the IAA of the 6th generation bronchi was not correlated with $\% \mathrm{FEV}_{1}$ in the supine position. Moreover, the correlation between the EAA and $\mathrm{FEV}_{1}$ was not greater in the 5th and 6th generation bronchi than that in the 4th generation. These results were not consistent with the previous reports showing that the IAA of 6th generation bronchi ${ }^{6}$ and EAA of 5th generation bronchi were more strongly correlated with $\% \mathrm{FEV}_{1}$ and $\mathrm{FEV}_{1}[10]$. This discrepancy could be explained by different sampling methods; for example, the previous studies only analysed selected airways, not all measurable airways. Further, the relatively small size of our study should also be noted.

Resting lung hyperinflation is a major manifestation of COPD. IC/TLC, which is known to be an indicator of resting hyperinflation, has been shown to predict mortality in patients with COPD [13], and deterioration of IC/TLC is associated with frequent exacerbations [31]. To the best of our knowledge, no study has reported an association between the spirometric indicator of lung hyperinflation and airway lumen area on the expiratory CT. The present study showed that the EAA and EAA/IAA can predict hyperinflation rather than airflow limitation. We emphasise that the EAA and IAA in the supine position did not correlate with IC/TLC, but the EAA and EAA/IAA of the distal bronchi were correlated with IC/TLC. Because of the complexity of the test, a lung volume measurement is not routinely recommended for patients with COPD. Recently, to reduce the spread of SARS-CoV-2, many pulmonary function testing laboratories have been closed or have significantly reduced their testing capacity [32]. Thus, the usefulness of upright CT evaluation of the airway lumen area for predicting lung hyperinflation might be clinically relevant for managing patients with COPD.

Some potential limitations of the present study should be discussed. First, the size of the study population was relatively small and had a relatively lower percentage of severe COPD patients. Second, the average age of the patients participating in our study was higher than that of other previous COPD clinical studies conducted in Western countries [33]. Further, the number of women was too low in our study. Previous reports have shown that airway wall thickness is related to sex, age, and smoking status [34]. Further studies with larger sample sizes, a representative percentage of severe COPD patients, and containing an appropriate number of women are needed. In addition, airway indices, such as the airway wall thickness at an internal perimeter of $10 \mathrm{~mm}$, have been reported to be associated with subjective symptoms and quality-of-life scores in COPD patients [35, 36]. Further studies with several airway indices are needed for understanding the relationship between the airway indices of upright $\mathrm{CT}$ and clinical parameters.

\section{Conclusion}

Upright CT quantification of the airway lumen area in patients with COPD revealed the difference in the airway lumen area between the supine and standing positions, and that the airway lumen areas on inspiratory and expiratory $\mathrm{CT}$ in the standing position are useful biomarkers for predicting airflow limitation and lung hyperinflation, respectively. Evaluation of airway lumen area using upright $\mathrm{CT}$ should be incorporated into a future COPD study. 


\section{Abbreviations}

COPD: Chronic obstructive pulmonary disease; CT: Computed tomography; IAA: Inspiratory airway lumen areas; EAA: Expiratory airway lumen areas; PFT: Pulmonary function test; IQR: Interquartile range; FEV1: Forced expiratory volume in $1 \mathrm{~s} ; \% \mathrm{FEV} 1$ : Forced expiratory volume in $1 \mathrm{~s}$ as a percentage of predicted forced expiratory volume in $1 \mathrm{~s}$; RV: Residual volume; \%RV: Residual volume as a percentage of predicted residual volume; IC/TLC: Inspiratory capacity/total lung capacity ratio.

\section{Acknowledgements}

The authors acknowledge Naomi Tamaki, Shiho Hirai, and Kyoko Komatsu for their valuable assistance. The authors acknowledge Shingo Nakayama and Kaori Sakurai for helping with data collection.

\section{Authors' contributions}

SC, YYA, MY, KF and MJ were responsible for the conception or design of the work; SC, YYA, MY, YYO, AT, SM, YN and HI, were responsible for the acquisition of data; SC, YYA, MY, YYO, WY and MM, analysed and interpreted the data; and SC, YYA, MY, YYO, AT, SM, YN, WY, HI, MM, KF and MJ drafted or revised the paper for important intellectual content and provided a final approval of the data. All authors read and approved the final manuscript.

\section{Funding}

This study was supported by Japan Society for the Promotion of Science (JSPS) KAKENHI (Grant Number 20K08056, and 17K16482).

\section{Availability of data and materials}

The datasets generated during and/or analysed during the current study are available from the corresponding author on reasonable request.

\section{Declarations}

\section{Ethics approval and consent to participate}

This study was registered on the University Hospital Medical Information Network (UMIN 000026587) and was approved by the ethics committees of Keio University and its affiliated hospitals (No. 20160385).

\section{Consent for publication}

Each patient provided written informed consent to analyze and publish his/ her data.

\section{Competing interests}

M.J. has received a grant from Canon Medical Systems. However, Canon Medical Systems was not involved in the design and conduct of the study, in the collection, analysis, and interpretation of the data, or in the preparation, review, and approval of the manuscript. The remaining authors have no conflicts of interest to declare.

\section{Author details}

${ }^{1}$ Division of Pulmonary Medicine, Department of Medicine, Keio University School of Medicine, 35 Shinanomachi, Shinjuku-ku, Tokyo 160-8582, Japan. 2 Department of Radiology, Keio University School of Medicine, 35 Shinanomachi, Shinjuku-ku, Tokyo 160-8582, Japan. ${ }^{3}$ Department of Clinical Laboratory, Keio University Hospital, 35 Shinanomachi, Shinjuku-ku, Tokyo 160-8582, Japan. ${ }^{4}$ Office of Radiation Technology, Keio University Hospital, 35 Shinanomachi, Shinjuku-ku, Tokyo 160-8582, Japan. ${ }^{5}$ Department of Laboratory Medicine, Keio University School of Medicine, 35 Shinanomachi, Shinjuku-ku, Tokyo 160-8582, Japan

Received: 5 February 2021 Accepted: 22 March 2021 Published online: 31 March 2021

\section{References}

1. Vogelmeier CF, Criner GJ, Martinez FJ, Anzueto A, Barnes PJ, Bourbeau J, et al. Global strategy for the diagnosis, management and prevention of chronic obstructive lung disease 2017 report: GOLD executive summary. Respirology. 2017;22:575-601.
2. Mead J, Turner JM, Macklem PT, Little JB. Significance of the relationship between lung recoil and maximum expiratory flow. J Appl Physiol. 1967:22:95-108.

3. Hogg JC, Macklem PT, Thurlbeck WM. Site and nature of airway obstruction in chronic obstructive lung disease. N Engl J Med. 1968;278:1355-60.

4. Nakano Y, Wong JC, de Jong PA, Buzatu L, Nagao T, Coxson HO, et al. The prediction of small airway dimensions using computed tomography. Am J Respir Crit Care Med. 2005;171:142-6.

5. Tanabe N, Shima H, Sato S, Oguma T, Kubo T, Kozawa S, et al. Direct evaluation of peripheral airways using ultra-high-resolution CT in chronic obstructive pulmonary disease. Eur J Radiol. 2019;120:108687.

6. Hasegawa M, Nasuhara Y, Onodera Y, Makita H, Nagai K, Fuke S, et al. Airflow limitation and airway dimensions in chronic obstructive pulmonary disease. Am J Respir Crit Care Med. 2006:173:1309-15.

7. Bodduluri S, Reinhardt JM, Hoffman EA, Newell JD Jr, Bhatt SP. Recent advances in computed tomography imaging in chronic obstructive pulmonary disease. Ann Am Thorac Soc. 2018;15:281-9.

8. Leong P, Tran A, Rangaswamy J, Ruane LE, Fernando MW, MacDonald $\mathrm{Ml}$, et al. Expiratory central airway collapse in stable COPD and during exacerbations. Respir Res. 2017:18:163.

9. Bhatt SP, Terry NL, Nath H, Zach JA, Tschirren J, Bolding MS, et al. Association between expiratory central airway collapse and respiratory outcomes among smokers. JAMA. 2016;315:498-505.

10. Matsuoka S, Kurihara Y, Yagihashi K, Hoshino M, Nakajima Y. Airway dimensions at inspiratory and expiratory multisection CT in chronic obstructive pulmonary disease: correlation with airflow limitation. Radiology. 2008:248:1042-9.

11. Kloth C, Thaiss WM, Ditt H, Hetzel J, Schulen E, Nikolaou K, et al. Segmental bronchi collapsibility: computed tomography-based quantification in patients with chronic obstructive pulmonary disease and correlation with emphysema phenotype, corresponding lung volume changes and clinical parameters. J Thorac Dis. 2016:8:3521-9.

12. Cooper CB. The connection between chronic obstructive pulmonary disease symptoms and hyperinflation and its impact on exercise and function. Am J Med. 2006;119:21-31.

13. Casanova C, Cote C, de Torres JP, Aguirre-Jaime A, Marin JM, Pinto-Plata V, et al. Inspiratory-to-total lung capacity ratio predicts mortality in patients with chronic obstructive pulmonary disease. Am J Respir Crit Care Med. 2005; 171:591-7.

14. Jinzaki M, Yamada Y, Nagura T, Nakahara T, Yokoyama Y, Narita K, et al. Development of upright computed tomography with area detector for whole-body scans: phantom study, efficacy on workflow, effect of gravity on human body, and potential clinical impact. Invest Radiol. 2020;55:73-83.

15. Yamada Y, Yamada M, Chubachi S, Yokoyama Y, Matsuoka S, Tanabe A, et al. Comparison of inspiratory and expiratory lung and lobe volumes among supine, standing, and sitting positions using conventional and upright CT. Sci Rep. 2020;10:16203.

16. Yamada Y, Yamada M, Yokoyama Y, Tanabe A, Matsuoka S, Niijima Y, et al. Differences in lung and lobe volumes between supine and standing positions scanned with conventional and newly developed 320-detector-row upright CT: intra-individual comparison. Respiration. 2020;99:598-605.

17. Narita K, Yamada Y, Yamada M, Yokoyama Y, Nakahara T, Jinzaki M. Pelvic floor morphology in the standing position using upright computed tomography: age and sex differences. Int Urogynecol J. 2020;31:2387-93.

18. Yamada $Y$, Jinzaki M, Hosokawa T, Tanami Y, Sugiura H, Abe T, et al. Dose reduction in chest $\mathrm{CT}$ : comparison of the adaptive iterative dose reduction 3D, adaptive iterative dose reduction, and filtered back projection reconstruction techniques. Eur J Radiol. 2012;81:4185-95.

19. American Association of Physicists in Medicine. The measurement, reporting, and management of radiation dose in CT; 2008. http://www. aapm.org/pubs/reports/rpt96.pdf. Accessed March 92021.

20. Mettler FA Jr, Huda W, Yoshizumi TT, Mahesh M. Effective doses in radiology and diagnostic nuclear medicine: a catalog. Radiology. 2008;248:254-63.

21. Nishimoto K, Karayama M, Inui N, Mori K, Kono M, Hozumi H, et al. Relationship between fraction of exhaled nitric oxide and airway morphology assessed by three-dimensional CT analysis in asthma. Sci Rep. 2017;7:10187

22. Miller MR, Hankinson J, Brusasco V, Burgos F, Casaburi R, Coates A, et al. Standardisation of spirometry. Eur Respir J. 2005;26:319-38. 
23. Graham BL, Steenbruggen I, Miller MR, Barjaktarevic IZ, Cooper BG, Hall $\mathrm{GL}$, et al. Standardization of spirometry 2019 update. An official American thoracic society and European respiratory society technical statement. Am J Respir Crit Care Med. 2019;200:e70-88.

24. Committee of Pulmonary Physiology, the Japanese Respiratory Society Guidelines for Pulmonary Function Tests: Spirometry, Flow-volume Curve, Diffusion Capacity of the Lung. Tokyo: Japanese Respiratory Society. 2004.

25. The Committee of Pulmonary Physiology JRS. Forced expiratory curve, flow volume curve and peak flow. In: The Clinical Respiratory Function Test 8th Edition. Tokyo: Medical Review 2016:312-21.

26. Beaumont M, Fodil R, Isabey D, Lofaso F, Touchard D, Harf A, et al. Gravity effects on upper airway area and lung volumes during parabolic flight. J Appl Physiol. 1985;1998(84):1639-45.

27. Bettinelli D, Kays C, Bailliart O, Capderou A, Techoueyres P, Lachaud $J$, et al. Effect of gravity on chest wall mechanics. J Appl Physiol. 1985;2002(92):709-16.

28. Boiselle PM, Michaud G, Roberts DH, Loring SH, Womble HM, Millett ME, et al. Dynamic expiratory tracheal collapse in COPD: correlation with clinical and physiologic parameters. Chest. 2012;142:1539-44.

29. Leong P, Bardin PG, Lau KK. What's in a name? Expiratory tracheal narrowing in adults explained. Clin Radiol. 2013;68:1268-75.

30. Shimizu K, Seto R, Makita H, Suzuki M, Konno S, Ito YM, et al. Computed tomography (CT)-assessed bronchodilation induced by inhaled indacaterol and glycopyrronium/indacaterol in COPD. Respir Med. 2016;119:70-7.
31. Park J, Lee CH, Lee YJ, Park JS, Cho YJ, Lee JH, et al. Longitudinal changes in lung hyperinflation in COPD. Int J Chron Obstruct Pulmon Dis. 2017; 12:501-8.

32. Kouri A, Gupta S, Yadollahi A, Ryan CM, Gershon AS, To T, et al. Addressing reduced laboratory-based pulmonary function testing during a pandemic. Chest. 2020;158:2502-10.

33. Lomas DA, Silverman EK, Edwards LD, Miller BE, Coxson HO, Tal-Singer $\mathrm{R}$, et al. Evaluation of serum CC-16 as a biomarker for COPD in the ECLIPSE cohort. Thorax. 2008;63:1058-63.

34. Hackx M, Bankier AA, Gevenois PA. Chronic obstructive pulmonary disease: CT quantification of airways disease. Radiology. 2012;265:34-48.

35. Grydeland TB, Dirksen A, Coxson HO, Eagan TM, Thorsen E, Pillai SG, et al. Quantitative computed tomography measures of emphysema and airway wall thickness are related to respiratory symptoms. Am J Respir Crit Care Med. 2010;181:353-9.

36. Martinez CH, Chen YH, Westgate PM, Liu LX, Murray S, Curtis JL, et al. Relationship between quantitative CT metrics and health status and BODE in chronic obstructive pulmonary disease. Thorax. 2012;67:399-406.

\section{Publisher's Note}

Springer Nature remains neutral with regard to jurisdictional claims in published maps and institutional affiliations.
Ready to submit your research? Choose BMC and benefit from:

- fast, convenient online submission

- thorough peer review by experienced researchers in your field

- rapid publication on acceptance

- support for research data, including large and complex data types

- gold Open Access which fosters wider collaboration and increased citations

- maximum visibility for your research: over $100 \mathrm{M}$ website views per year

At BMC, research is always in progress.

Learn more biomedcentral.com/submissions 